\title{
Record of Decision \\ for the \\ Electrical Interconnection of the \\ COB Energy Facility
}

\section{DECISION}

The Bonneville Power Administration (BPA) has decided to offer contract terms for interconnection of the COB Energy Facility with the Federal Columbia River Transmission System (FCRTS), as proposed in the COB Energy Facility Final Environmental Impact Statement (FEIS) (DOE/EIS-0343, June 2004). Proposed by Peoples Energy Resources Company (PERC), the COB Energy Facility involves constructing and operating a new 1,160megawatt (MW) natural gas-fired, combined-cycle power generation facility at a 50.6-acre site near Bonanza in Klamath County, Oregon, and a 7.2-mile-long 500-kilovolt (kV) transmission line south to BPA's Captain Jack Substation. A Generation Interconnection Agreement with PERC would provide for interconnection of the COB Energy Facility with the FCRTS and electrical generation in the BPA Control Area. In addition, a Construction, Operations and Maintenance Agreement would provide for construction of interconnection facilities (i.e., installing additional electrical equipment at Captain Jack Substation), and continued operations and maintenance of interconnection equipment.

\section{BACKGROUND}

BPA is a Federal agency that owns and operates the majority of the high-voltage electric transmission system in the Pacific Northwest, the FCRTS. BPA has adopted an Open Access Transmission Tariff for the FCRTS, consistent with the Federal Energy Regulatory Commission's (FERC) pro forma open access tariff. ${ }^{1}$ Under BPA's tariff, BPA offers transmission interconnection to the FCRTS to all eligible customers on a first-come, first-served basis, subject to an environmental review under the National Environmental Policy Act (NEPA).

In October 2001, PERC submitted a transmission interconnection request to BPA for interconnection of the proposed COB Energy Facility with the FCRTS. In considering the request, BPA prepared an EIS to evaluate the environmental effects of the proposed interconnection and related actions, issuing the FEIS in June 2004. BPA must respond to the request consistent with BPA's Transmission Tariff.

\section{PROJECT DESCRIPTION}

The COB Energy Facility would be constructed on a site near the rural community of Bonanza, in Klamath County, Oregon. Generating components of the project would be constructed in either one or two phases, including four air-cooled combustion turbine generators fueled with

\footnotetext{
${ }^{1}$ Although BPA is not subject to FERC's jurisdiction, BPA follows the open access tariff as a matter of national policy. This course of action demonstrates BPA's commitment to non-discriminatory access to its transmission system and ensures that BPA will receive non-discriminatory access to the transmission systems of utilities that are subject to FERC's jurisdiction.
} 
natural gas, four heat recovery steam generators, and two steam turbines. Additional facilities include a new 7.2-mile-long 500-kV transmission line, a new 4.1-mile-long natural gas pipeline, a 2.8-mile-long water pipeline, a 20-acre wastewater evaporation pond or a 3,770-foot-long irrigation pipeline to deliver wastewater to a 31-acre pasture, a 4.7-acre stormwater infiltration basin, a 1.5-acre stormwater retention pond, and various tanks, buildings, exhaust stacks, parking, and storage areas.

Natural gas to fuel the combustion turbines would be supplied by way of a new 4.1-mile-long, 20-inch-diameter pipeline from a Gas Transmission Northwest's Bonanza Compressor Station. The new pipeline would be constructed within private easements adjacent to or near Klamath County road rights-of-way.

Although COB Energy Facility generators would use air-cooled condensers, the project would use an average of 72 gallons per minute for steam production and station service, up to a maximum of 210 gallons per minute. The source of this water would be one existing and two new wells near the project site, drawing from a deep aquifer consistent with a State of Oregon water right permit expected to be incorporated into the State energy facility site certificate. Process wastewater would either be used to irrigate pasture or held in a lined pond to evaporate. Sanitary water would be routed to an onsite septic tank then discharged to a leach field. No wastewater would be discharged to surface waters.

The COB Energy Facility would interconnect to the FCRTS at Captain Jack Substation, 7.2 miles south of the project site. PERC would construct a new 500-kV transmission line from the project site to Captain Jack Substation. Part of the transmission line would cross public land managed by the Bureau of Land Management. BPA would install additional electrical equipment at Captain Jack Substation. At this time, PERC has not requested specific points of delivery.

\section{ALTERNATIVES CONSIDERED}

Two alternatives were evaluated in the EIS: the proposed action, and the No Action alternative. Other alternatives were considered but rejected for various reasons, as explained in the EIS.

\section{Proposed Action}

The action proposed by BPA and evaluated in the EIS was to provide the interconnection services requested by PERC. A reasonably foreseeable consequence of granting this interconnection is development of the proposed COB Energy Facility, including the proposed 7.2-mile transmission line that would interconnect to the FCRTS at BPA's existing Captain Jack Substation. Even though BPA has no jurisdiction or supervision over, or ownership or financial involvement in, the proposed generation facility, the potential environmental effects associated with this facility have been evaluated in the EIS and considered by BPA decision-makers.

\section{No Action Alternative}

As an alternative to the interconnection, BPA considered not providing the services requested. Without the requested interconnection, the COB Energy Facility could not operate and would 
therefore not be built. Because there would be no change in existing conditions, the No Action alternative is the environmentally preferred alternative.

\section{RATIONALE FOR DECISION}

I have decided it is in the best interest of BPA and the Pacific Northwest to offer contract terms (i.e., a Generation Interconnection Agreement) for interconnection of the COB Energy Facility into the FCRTS at BPA's Captain Jack Substation. The selected alternative best satisfies relevant factors identified in the EIS:

- Provide an adequate, economical, efficient and reliable power supply to the Pacific Northwest, and the electrical stability and reliability of the FCRTS;

- Consistency with BPA's environmental and social responsibilities; and

- Cost and administrative efficiency.

The COB Energy Facility will provide economic and reliable energy, helping to modernize the national energy supply as envisioned by the National Energy Policy. Offering a Generation Interconnection Agreement is in accordance with BPA's Open Access Transmission Tariff. The Generation Interconnection Agreement will include provisions as necessary to ensure the continuing safe, reliable operation of the FCRTS. While rejecting the requested interconnection would not threaten the FCRTS, it would be contrary to BPA's Open Access Transmission Tariff and would not enhance the power supply available to the Nation or to the Pacific Northwest.

Controversial issues associated with the COB Energy Facility most notably involve land use, water use and disposal, and air emissions. All of these issues fall under the jurisdictions of various State and Federal regulatory agencies for appropriate resolution through the applicable regulatory processes. The Generation Interconnection Agreement will include provisions requiring PERC to acquire all necessary permits before the Agreement is implemented, including a Site Certificate from Oregon's Energy Facility Siting Council. BPA expects PERC and the COB Energy Facility to comply with terms and conditions of all permits issued. A Construction, Operations and Maintenance Agreement will also include appropriate provisions for remediation of oil or other hazardous substances associated with construction and operation of related electrical facilities in a manner consistent with applicable Federal, State, and local laws. I find no unusual environmental circumstances or inconsistencies with BPA's environmental and social obligations to warrant rejection of the requested interconnection.

Finally, interconnection of the COB Energy Facility with the FCRTS and selling transmission services to PERC would provide financial benefits to BPA and therefore to BPA ratepayers. In contrast, rejecting the requested interconnection would provide no such benefits.

\section{MITIGATION}

All practicable means to avoid or minimize environmental harm from the alternative selected have been adopted. These mitigation measures are identified in the EIS. If and when the COB 
Energy Facility is constructed, it would be in accordance with permit conditions specified by appropriate regulatory agencies.

Issued in Portland, Oregon.

/s/ Stephen J. Wright

Stephen J. Wright

Administrator and

Chief Executive Officer
August 20, 2004

Date 